\title{
Твердый раствор PbSnTe:In - уровни захвата, гальваномагнитные свойства и ТГц фоточувствительность
}

\author{
(С) Д.В. Ищенко, А.Э. Климов, В.Н. Шумский, В.С. Эпов
}

Институт фризики полупроводников им. А.В. Ржанова

Сибирского отделения Российской академии наук, 630090 Новосибирск, Россия

E-mail: miracle4348@gmail.com

(Получена 27 апреля 2016 г. Принята к печати 10 мая 2016 г.)

Рассмотрена модель $\mathrm{Pb}_{1-x} \mathrm{Sn}_{x} \mathrm{Te}: \mathrm{In}$, основанная на представлениях теории неупорядоченных систем, проведены расчеты температурных зависимостей положения уровня Ферми и концентрации носителей заряда в зависимости от уровня легирования индием и их сравнение с экспериментальными данными. Проведен расчет нестационарных вольт-амперных характеристик в режиме инжекции из контакта и ограничения тока пространственным зарядом при различных скоростях изменения напряжения, выполнено сравнение полученных данных с экспериментом и показано, что вид характеристик определяется параметрами захвата электронов на локализованные состояния. Исследованы релаксации фототока в магнитном поле и обсужден механизм таких релаксаций в предположении о магнитном вымораживании носителей заряда.

\section{1. Введение}

Уникальным свойством твердого раствора $\mathrm{Pb}_{1-x} \mathrm{Sn}_{x}$ Те : In является инверсия зоны проводимости и валентной зоны [1]. Точка инверсии зон (бесщелевое состояние) зависит от температуры и состава твердого раствора. Среди других необычных свойств материала при малой ширине его запрещенной зоны особый интерес вызывают:

- резкое уменьшение проводимости в темноте при температуре $T \leq 20 \mathrm{~K}$ (так называемый переход „металл-диэлектрик“), которое связывается со стабилизацией уровня Ферми в запрещенной зоне для определенного состава $(x \approx 0.22-0.29)[2-5]$;

- долговременная релаксация фотосигнала и остаточная проводимость после выключения освещения [2,3];

- высокая фоточувствительность - наличие реакции на крайне слабое излучение, в том числе от тел, нагретых до температур, лишь ненамного превышающих температуру образцов $[2,3]$;

- наличие фоточувствительности вплоть до субмиллиметровой (терагерцовой) области спектра [6-8]. Имеются сведения о том, что длина волны чувствительности материала достигает 496 мкм [7].

Авторы [5] нашли, что положение уровня индия, которое они связали с положением уровня Ферми, изменяется линейно от содержания олова, начиная от его положения в зоне проводимости теллурида свинца, приближаясь к середине запрещенной зоны при $x=0.24-0.26$ и заканчивая выходом в валентную зону при $x \approx 0.29$. Однако причины такого поведения уровня индия и стабилизации на нем уровня Ферми определены не были, как и причины того, почему переход „металл-диэлектрик“ происходит только внутри определенного диапазона составов. Для описания эффекта стабилизации уровня Ферми авторами $[9,10]$ была предложена модель спонтанной диссоциации нейтральной примеси, в соответствии с которой атомы индия диссоциируют на пары ионов, заряженных положительно и отрицательно относительно заряда металлического узла в решетке PbSnTe. При этом соответствующий акцепторный уровень лежит выше донорного уровня, т.е. энергия Хаббарда отрицательна. Авторы показали, что при больших концентрациях индия происходит стабилизация уровня Ферми вблизи середины запрещенной зоны. В дальнейшем эта теория была развита в работе [11]. В полупроводниковых соединениях $\mathrm{A}^{\mathrm{IV}} \mathrm{B}^{\mathrm{VI}}$ атомы металлов (свинец или олово в $\mathrm{PbSnTe}$ ) находятся в двухвалентном состоянии (конфигурация $s^{2} p^{2}$ ). Атом примеси третьей группы, который замещает двухвалентный атом металла, в основном (одновалентном) состоянии является однозарядовым акцептором; в двухвалентном состоянии $\left(s^{1} p^{2}\right)$ примесь будет нейтральна и парамагнитна (неспаренный электрон в $s$-оболочке), в трехвалентном состоянии атом примеси будет являться однозарядовым донором. Авторы показали, что преобладание одного из состояний определяется положением уровня Ферми в кристалле. При совпадении энергий двух различных состояний в системе происходит перераспределение зарядов, что приводит к стабилизации уровня Ферми.

Объяснению большой фоточувствительности и долговременной релаксации (ДР) фототока посвящено много работ. В работе [3] высказано предположение о том, что причиной долговременной релаксации фототока является захват носителей заряда на ловушки. В то же время в течение долгого времени в литературе преобладала гипотеза о ян-теллеровской (ЯТ) неустойчивости кристаллического окружения точечных дефектов, ведущей к понижению энергетического уровня при захвате электрона на ЯТ-центр [11-14]. При этом время перехода электрона из зоны проводимости на ЯТ-центр и обратно носит термоактивационный характер с энергией активации около 0.01 эВ [14], что при гелиевых температурах 
ведет к увеличению времени релаксации до $10^{12}$ раз по сравнению с ситуацией, когда барьер отсутствует. Однако такая гипотеза относится к примесной фотопроводимости и не описывает ДР фотопроводимости при межзонных переходах [15]. В работе [16] авторы объяснили резкий спад подвижности при низких температурах, максимум в температурной зависимости сопротивления, $N$-образную зависимость тока от поля в рамках трехзонной модели, в которой нижняя примесная зона, по которой осуществляется туннельно-прыжковая проводимость, и верхняя зона разделены потенциальным барьером. При возбуждении излучением электроны из нижнего состояния переходят в верхнее - проводящее, а их рекомбинация затруднена из-за барьера. Поэтому после выключения освещения электроны будут находиться в верхнем состоянии длительное время, которое определяется некоторой характеристической температурой и величиной барьера. Эта модель в принципе может объяснить ДР фототока, резкий спад подвижности и температурные зависимости сопротивления, однако не содержит никаких предположений о причинах возникновения такой зонной конфигурации.

Цель настоящей работы - рассмотрение модели $\mathrm{PbSnTe}: \mathrm{In}$, основанной на представлениях теории неупорядоченных систем, расчет температурных зависимостей положения уровня Ферми и концентрации носителей заряда, а также анализ нестационарных вольт-амперных характеристик (BAX) и релаксаций фототока в магнитном поле, связанных с образованием спектра локализованных состояний.

\section{2. Твердый раствор $\mathrm{Pb}_{1-x} \mathrm{Sn}_{x} \mathrm{Te}:$ In как неупорядоченная система. Модель для расчетов, эксперимент}

\section{1. Обоснование модели}

В общем случае в [17-19] к неупорядоченным системам относят такую макроскопическую систему частиц, в которой отсутствует дальний порядок. К таким системам, в частности, относят сильно легированные полупроводники, металлические сплавы, аморфные и стеклообразные вещества и др. Так, в сильно легированных полупроводниках неупорядоченность обусловлена хаотическим расположением примесных атомов, в стеклообразных веществах неупорядоченность обусловлена пространственными флуктуациями в расположении атомов. К неупорядоченным системам относят сплавы, в которых нарушение дальнего порядка обусловлено конечной вероятностью нахождения компонента сплава в узле решетке. В модели Андерсона [20] в качестве изменяемого параметра взята относительная величина беспорядка - отношение интеграла перекрытия волновых функций $J$ к разбросу атомных потенциалов атомов $W(J / W)$. В сплаве образуются энергетические состояния, которые разбросаны в интервале энергий $W$.
Если $J / W>(J / W)_{\text {crit, }}$ где $(J / W)_{\text {crit }}$ - некая критическая величина, то происходит делокализация состояний, в противном случае состояния остаются локализованными. В модифицированной версии модели Андерсона [21] энергетический спектр состояний в запрещенной зоне состоит из доноров и акцепторов, причем энергия Хаббарда отрицательна.

Представляется, что такой подход применим к твердому раствору $\mathrm{Pb}_{1-x} \mathrm{Sn}_{x} \mathrm{Te}:$ In. Случайность расположения атомов свинца и олова в узлах решетки дополняется также случайным расположением атомов индия в узлах металлической подрешетки. Это, по-видимому, и является причиной образования состояний (подзон) в запрещенной зоне. Авторы [22] описывают особенности процесса легирования индием следующим образом. Исходные образцы $\mathrm{Pb}_{1-x} \mathrm{Sn}_{x} \mathrm{Te}: \mathrm{In}$ с содержанием олова $x=0.22$, полученные из газовой фазы при температурах $800-830^{\circ} \mathrm{C}$, обладали $p$-типом проводимости. Индий вводился во время роста монокристаллов, его концентрация менялась в диапазоне от 0.2 до 4 ат\%. Авторы пришли к заключению, что при низких концентрациях (до $0.8 \%$ ) атомы индия встраиваются в металлическую подрешетку матрицы. Это приводит к уменьшению концентраций вакансий металла и носителей заряда по сравнению с нелегированными образцами. При дальнейшем увеличении концентрации индия образуется соединение типа $\operatorname{In}_{2} \mathrm{Te}_{3}$, которое в конечном итоге выпадает в отдельную фазу. При этом это соединение является электрически пассивным, т. е. увеличение концентрации индия не приводит к увеличению концентрации носителей заряда.

\section{2. Модель и расчеты}

Наши представления о влиянии индия сводятся к следующему. До легирования в $\mathrm{Pb}_{1-x} \mathrm{Sn}_{x}$ Те имеются вакансии теллура и металлов с малой энергией активации, которые определяют тип проводимости и концентрацию свободных носителей заряда. На первом этапе легирования индий встраивается на место вакансий металла, что приводит к уменьшению концентрации акцепторов и понижению изначальной концентрации носителей заряда, как в [22]. Одновременно в соответствии с [20,21] возникают акцепторные и донорные локализованные состояния (подзоны), которые при выполнении критерия $J / W>(J / W)_{\text {crit }}$ могут делокализоваться. При увеличении концентрации индия и заполнения вакансий металла он может встраиваться также в междоузлия, где играет роль донора.

При проведении расчетов предполагалось, что в исходном материале имеются только вакансии теллура и металла, которые являются мелкими донорами и акцепторами. Также полагалось, что в результате легирования индием возникает неупорядоченность с образованием как акцепторных, так и донорных состояний (подзон), а большие концентрации индия ведут к возникновению и донорных уровней. 


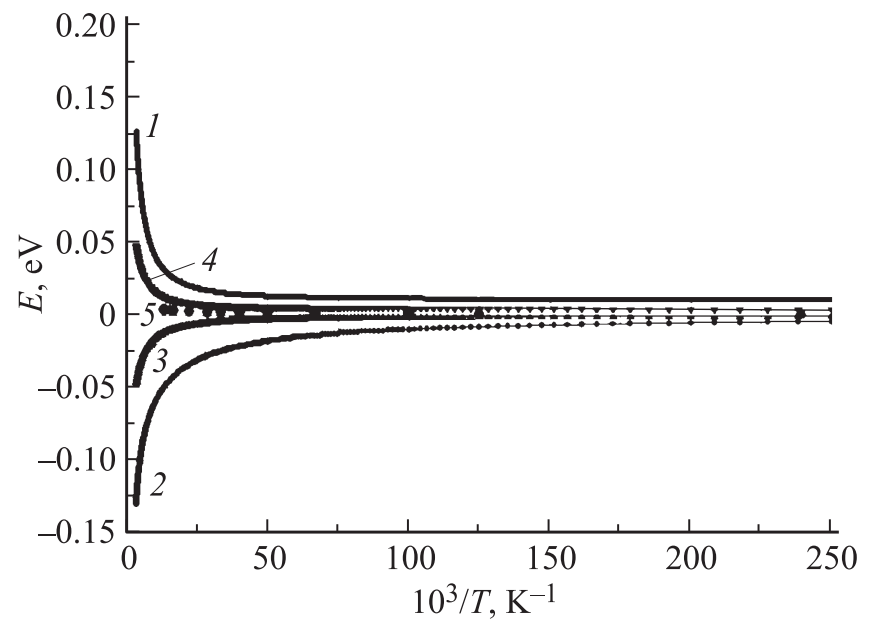

Рис. 1. Расчетные температурные зависимости положения в образце $\mathrm{Pb}_{0.67} \mathrm{Sn}_{0.33} \mathrm{Te}:$ In дна зоны проводимости $E_{c}$ (1) и уровня Ферми $E_{\mathrm{F}}(2-4)$. В расчетах исходная концентрация мелких акцепторов $N_{a 0}=5 \cdot 10^{20} \mathrm{~cm}^{-3}$. Концентрация индия $N_{\text {In }}$ равна, см ${ }^{-3}: 0(2), 6.5 \cdot 10^{19}(3), 4.5 \cdot 10^{20}(4)$. 5 (круги) - экспериментальные данные, $N_{\text {In }} \approx 1.0 \cdot 10^{20} \mathrm{~cm}^{-3}$.

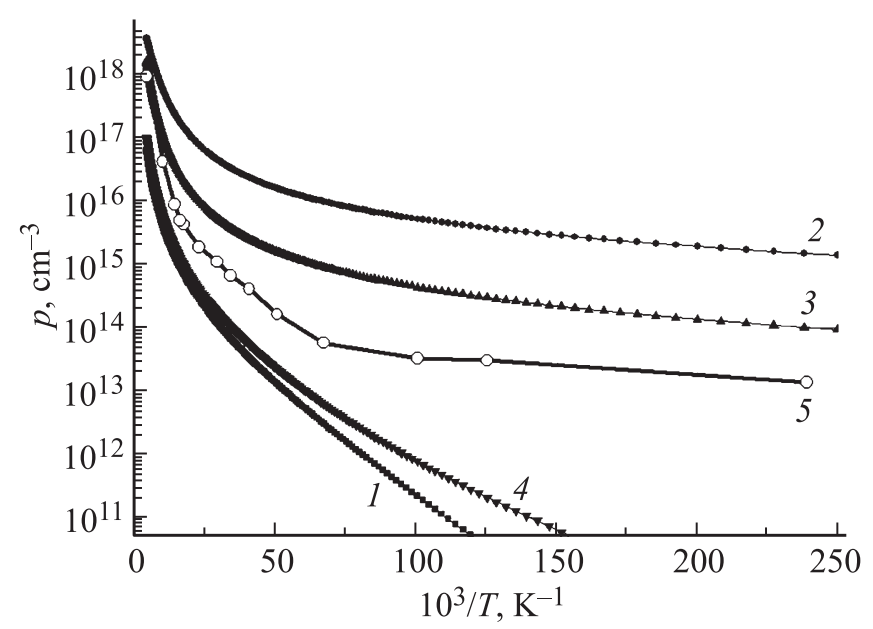

Рис. 2. Расчетные (1-4) и экспериментальная (5) температурные зависимости концентрации дырок в образце $\mathrm{Pb}_{0.67} \mathrm{Sn}_{0.33} \mathrm{Te}:$ In. В расчетах $N_{a 0}=5 \cdot 10^{20} \mathrm{~cm}^{-3} .1-$ собственная концентрация $N_{i}$. Для кривых $2-4$ концентрация $N_{\text {In }}$ равна, $\mathrm{cm}^{-3}: 0(2), 6.5 \cdot 10^{19}(3), 4.5 \cdot 10^{20}(4) .5$ - эксперимент, $N_{\text {In }}-1 \cdot 10^{20} \mathrm{~cm}^{-3}$.

\section{3. Температурная зависимость положения уровня Ферми}

Результат расчетов температурной зависимости положения уровня Ферми для набора начальных параметров пленки, обладающей без легирования проводимостью $p$-типа, приведен на рис. 1. На нем же показано положение дна зоны проводимости. Отсчет энергии велся от потолка валентной зоны $E_{v}=0$. Параметры расчетов указаны в подписи к рисунку.
Из рисунка видно, что при увеличении температуры от $4.2 \mathrm{~K} \quad\left(1000 / T \approx 250 \mathrm{~K}^{-1}\right)$ до $15-20 \mathrm{~K}$ $\left(1000 / T \approx 50-70 \mathrm{~K}^{-1}\right) E_{\mathrm{F}}$ меняется незначительно, но имеет разную величину в зависимости от исходных параметров пленки и в особенности от соотношения концентрации индия и концентрации вакансий металла.

Аналогичные температурные зависимости $E_{\mathrm{F}}$ были получены и для других составов, в том числе для $\mathrm{Pb}_{0.76} \mathrm{Sn}_{0.24} \mathrm{Te}: \mathrm{In}\left(N_{a 0}=5 \cdot 10^{20} \mathrm{~cm}^{-3}\right)$, что близко к составу, исследованному в [22]. Для этого состава положение $E_{\mathrm{F}}$ слабо меняется в области $T=4.2-(15-20) \mathrm{K}$, а при дальнейшем увеличении температуры, как и на рис. 1 , поведение зависимости $E_{\mathrm{F}}(1 / T)$ определяется соотношением между концентрациями индия и вакансий металла.

Рассчитанные по модели температурные зависимости концентрации дырок для $\mathrm{Pb}_{0.67} \mathrm{Sn}_{0.33} \mathrm{Te}: \mathrm{In}$, а также экспериментальные данные, полученные из измерений эффекта Холла, представлены на рис. 2.

Расчет (кривые 2-4) показывает, что по мере увеличения концентрации введенного индия концентрация дырок уменьшается при всех температурах, приближаясь к собственной концентрации носителей заряда. Экспериментальные данные согласуются с расчетными значениями, что говорит о близости исходной концентрации вакансий металла к заданной в расчете $N_{a 0}=5 \cdot 10^{20} \mathrm{~cm}^{-3}$.

\section{4. Нестационарные вольт-амперные характеристики}

Наличие центров захвата вызывает появление не только ДР концентрации фотовозбужденных носителей

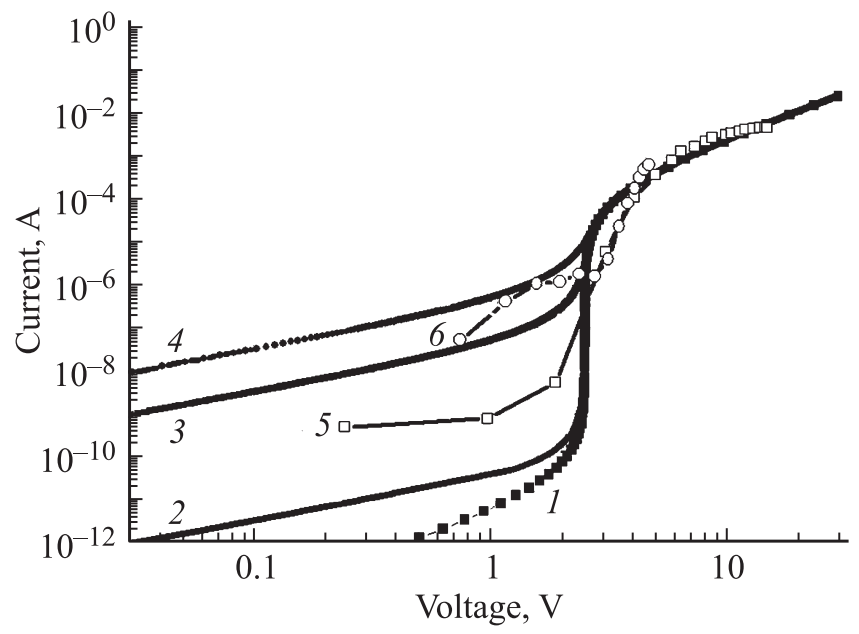

Рис. 3. Расчетные (1-4) и экспериментальные $(5,6)$ ВАХ в режиме ТОПЗ. 1 - квазистационарная ВАХ (уровни прилипания находятся в равновесии со свободными носителями заряда). Нестационарные расчетные ВАХ, скорость нарастания напряжения $\alpha$ равна, B/c: $3 \cdot 10^{-6}(2), 3 \cdot 10^{-4}(3), 3 \cdot 10^{-2}(4)$. Экспериментальные ВАХ, $\alpha$, равны, В/с: $3.3 \cdot 10^{-2}(5), 3.3$ (6) 
заряда (фотопроводимости), но и трансформацию вольтамперных характеристик (BAX) при различных временах развертки напряжения на образце.

Были проведены расчеты ВАХ в стационарном и нестационарном режимах для образца на основе пленки $\mathrm{PbSnTe}:$ In при наличии только одного уровня прилипания. В расчетах концентрация ловушек была взята $M=1 \cdot 10^{9} \mathrm{~cm}^{-3}$, коэффициент захвата электронов на уровень прилипания $\gamma=1 \cdot 10^{-3} \mathrm{~cm}^{3} / \mathrm{c}$, скорость возрастания напряжения менялась от $\alpha=3 \cdot 10^{-6} \mathrm{~B} / \mathrm{c}$ до $\alpha=3 \cdot 10^{-2} \mathrm{~B} / \mathrm{c}$. Результаты расчета и экспериментальные ВАХ для двух значений $\alpha$ приведены на рис. 3 .

\section{5. Релаксации тока в магнитном поле}

Релаксации тока при быстром включении и выключении магнитного поля $B$ как без, так и при освещении образцов измерялись на структуре в геометрии диска Карбино с диаметром внутреннего электрода $0.2 \mathrm{~cm}$ и величиной зазора между электродами $0.032 \mathrm{~cm}$. Образцы располагались в экранированной от фонового излучения камере, внутри которой находился источник освещения - светодиод (СД) видимого диапазона. Резкое „включение“ и „выключение“ магнитного поля напряженностью 4 Тл, ориентированного перпендикулярно плоскости подложки, производилось посредством быстрого (0.1-0.3c) механического перемещения камеры с образцом в сверхпроводящий соленоид и обратно. Далее описаны результаты измерений для одного из образцов со следующими основными параметрами: толщина пленки $d=0.00013 \mathrm{~cm}$, содержание олова $x=0.295 \pm 0.001$, концентрация атомов $\mathrm{In}$ $0.32 \pm 0.02 \mathrm{aT} \%$, тип проводимости без освещения электронный, тип проводимости при освещении при $T=4.2 \mathrm{~K}-$ дырочный, максимальная измеренная подвижность электронов $\mu_{n}=4.5 \cdot 10^{4} \mathrm{~cm}^{2} \cdot \mathrm{B}^{-1} \cdot \mathrm{c}^{-1}$ (при $T=20 \mathrm{~K}$ ), подвижность дырок при освещении $\mu_{p}=1.7 \cdot 10^{4} \mathrm{~cm}^{2} \cdot \mathrm{B}^{-1} \mathrm{c}^{-1}$ (при $T=4.2 \mathrm{~K}$ ), минимальная измеренная концентрация электронов без освещения $n=1.8 \cdot 10^{11} \mathrm{~cm}^{-3}$ (при $T=20 \mathrm{~K}$ ). Достоверное определение величин $n$ и $\mu$ без освещения при $T<20 \mathrm{~K}$ из измерений эффекта Холла было невозможным из-за высокого сопротивления образца.

BAX образца без освещения имели нелинейный характер, типичный для режима ТОПЗ, с изменением тока при $B=0$ в диапазоне от $\sim 1 \cdot 10^{-9} \mathrm{~A}$ при $U \approx 0.03 \mathrm{~B}$ до $\sim 0.075$ А при $U \approx 0.8$ В. Относительное уменьшение тока без освещения в магнитном поле по сравнению с током при $B=0$ зависело от его величины $I_{B=0}$. Наиболее ярко особенности релаксации тока при „включении“ и „выключении“ магнитного поля без освещения проявлялись при достаточно большой величине $I_{B=0}$, когда его уменьшение в магнитном поле $B=4$ Тл достигало 3-4 порядков и более. При этом на временни́х зависимостях уменьшения тока при „включении“ магнитного поля наблюдалось несколько характерных времен. При
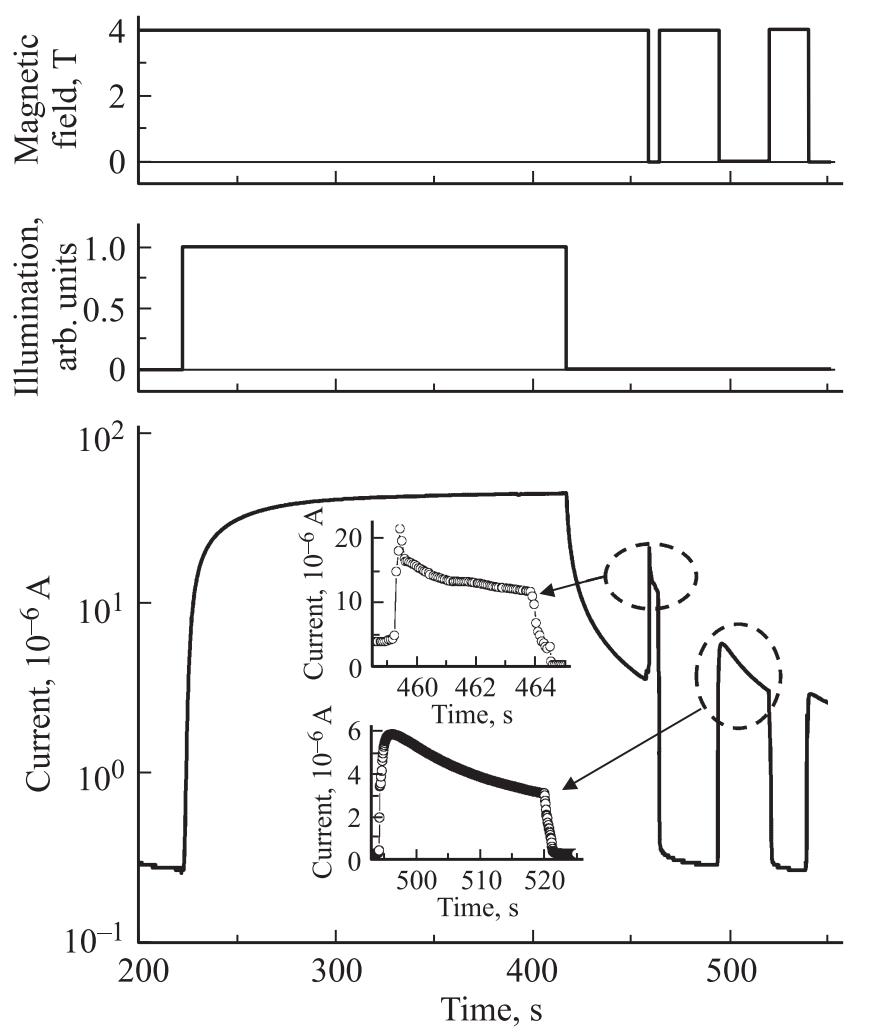

Рис. 4. Временнб́е зависимости тока (внизу), магнитного поля (посередине) и освещения (вверху). На вставках нижнего рисунка в увеличенном масштабе приведены фрагменты временно́й зависимости тока.

„Выключении“ магнитного поля возврат тока к исходному значению носил ступенчатый характер с разными характерными временами.

Также были исследованы временные зависимости изменения тока при комбинированном включении и выключении как освещения, так и магнитного поля. Пример такой зависимости показан на рис. 4 вместе с временны́ми зависимостями магнитного поля и освещения.

Напряжение на структуре равнялось $U=0.2 \mathrm{~B}$. После включения освещения $(t=220$ с на рис. 4) при „включенном“ магнитном поле ток возрастал примерно на 2.5 порядка с выходом на насыщение. После выключения освещения $(t=417 \mathrm{c})$ фототок начинал уменьшаться по неэкспоненциальному закону. Затем в момент времени $t=458$ с магнитное поле было „выключено“, после чего произошло резкое - почти на порядок - увеличение тока. Повторное „включение“ магнитного поля при $t=464 \mathrm{c}$ привело к уменьшению тока почти на 2 порядка (примерно на порядок по сравнению с величиной, которая была на момент „выключения“ поля). Таким образом, можно сказать, что кратковременное выключение магнитного поля в процессе релаксации фототока приводило к его резкому - примерно на порядок - уменьшению („гашению“ фототока).

Процедура „выключения“ и „включения“ магнитного поля была повторена несколько раз. Из рисунка видно, 
что фрагменты верхней („выключенное“ магнитное поле) и нижней („включенное“ магнитное поле) частей зависимости на участке релаксации фототока выглядят как фрагменты двух разных релаксационных зависимостей. Оценки постоянных времени дали значения примерно 20 с для верхней и около 45 с для нижней зависимостей. Из рисунков на вставках также видно, что формы кривых релаксации фототока после первого и второго „выключения“" магнитного поля значительно отличаются друг от друга. В первом случае (верхняя вставка) релаксация идет не только быстрее, но на зависимости тока от времени просматривается несколько „изломов“, отсутствующих во втором случае, для которого поведение тока от времени носит плавный характер.

\section{3. Обсуждение результатов}

\section{1. $\mathrm{Pb}_{1-x} \mathrm{Sn}_{x} \mathrm{Te}:$ In как неупорядоченная система}

Представления о твердом растворе $\mathrm{Pb}_{1-x} \mathrm{Sn}_{x} \mathrm{Te}: \mathrm{In}$ как неупорядоченной системе, в которой образуются донорные и акцепторные подзоны, на первый взгляд не слишком отличаются от представлений о спонтанной диссоциации атомов $2 \mathrm{In}^{2+} \rightarrow \mathrm{In}^{1+}+\mathrm{In}^{3+}$ с образованием донорных и акцепторных уровней $[9,10]$. Однако существуют два экспериментальных факта, которые находят объяснение именно в представлениях о $\mathrm{Pb}_{1-x} \mathrm{Sn}_{x} \mathrm{Te}: \mathrm{In}$ как неупорядоченной системе. Первый из них заключается в наблюдении фототока при воздействии излучения в области до длин волн $\lambda \approx 500$ мкм. При этом в диапазоне 100-200 мкм фототок наблюдается при непрерывном изменении длины волны, что может быть только в случае квазинепрерывного спектра состояний. Второй факт состоит в уменьшении подвижности при температуре ниже $20 \mathrm{~K}$ [6]. И первый и второй факты могут быть объяснены наличием подзон в запрещенной зоне. Фототок при $\lambda \geq 100$ мкм тогда связан с переходами электронов с уровней, составляющих подзону, в зону проводимости, причем эти переходы носят непрерывный характер по энергии. Уменьшение подвижности определяется уменьшением концентрации свободных носителей заряда в разрешенных зонах и преобладанием проводимости по подзоне, как например в сильно легированных полупроводниках, что в данном случае может быть связано с делокализацией уровней. Характерно, что при измерении эффекта Холла в условиях оптического возбуждения наблюдаются высокие значения подвижности, что связано с транспортом в зоне проводимости.

Расчеты и экспериментальные данные, приведенные на рис. 1 и 2, хотя и не противоречат друг другу, только качественно объясняют направление изменения свойств $\mathrm{PbSnTe}$ при введении индия. Препятствием для точных количественных расчетов параметров конкретного образца при его легировании индием является невозможность определения соотношения между концентрациями собственных точечных дефектов в нелегированном образце. Тем не менее из рассмотренной модели следует, что изменение положения уровня Ферми при изменении состава, о котором говорилось во Введении, может быть не связано непосредственно с изменением содержания олова, как это описано в [5], а определяться, в частности, изменением концентрации вакансий металла при изменении состава $\mathrm{PbSnTe}$.

\section{2. Нестационарные явления}

Наличие подзон или квазинепрерывного спектра электронных состояний в запрещенной зоне $\mathrm{PbSnTe}: \mathrm{In}$ должно вести и к наблюдению специфических особенностей нестационарных явлений, ярким примером которых являются хорошо известные неэкспоненциальные ДР фототока. Особенности нестационарных ВАХ в режиме ТОПЗ, приведенные в данной работе, также качественно соответствуют этой модели. При достаточно большой скорости возрастания напряжения и соответствующих параметрах уровней прилипания инжектированные в объем электроны не успевают захватываться на них. В этом случае форма ВАХ близка к зависимости тока от напряжения в диэлектрике без ловушек $\left(I \sim U^{2}\right)$. При уменьшения скорости развертки напряжения происходит частичное заполнение ловушек, а затем переход к стационарной BAX. При этом ток в области малых напряжений (до полного заполнения центров захвата) значительно меньше, чем ток в образце без ловушек или в случае, когда ловушки не успевают заполняться изза большой скорости изменения напряжения. Результаты расчетов BAX, приведенные на рис. 3, носят качественный характер и сделаны в рамках упрощенной модели. Так, в модель заложен только один уровень прилипания, следствием чего является резкое увеличение тока в области напряжений полного заполнения ловушек (около 2-3 В на рис. 3, кривые 1-4). В эксперименте соответствующая область напряжений значительно шире (около 1-4В на рис. 3, зависимости 5-6). Последнее однозначно говорит о наличии, как минимум, спектра уровней прилипания или об их непрерывном распределении, как это и следует из модели. Вместе с тем расчеты качественно соответствуют эксперименту, а именно увеличение скорости нарастания напряжения ведет к трансформации формы ВАХ с тенденцией перехода к форме, соответствующей случаю отсутствия ловушек.

Релаксационные особенности тока при включении и выключении магнитного поля (рис. 4) могут быть объяснены магнитным вымораживанием носителей заряда [23]. Оно заключается в уменьшении концентрации носителей заряда с ростом магнитного поля, наблюдается в узкозонных полупроводниках с высокой подвижностью носителей заряда при низких температурах и связано с ростом энергии ионизации примесей. Для $B=4$ Тл условие сильного магнитного поля $\mu B \geq 1$, необходимое 
для магнитного вымораживания, выполняется при значении подвижности $\mu \geq 2500 \mathrm{~cm}^{2} \cdot \mathrm{B}^{-1} \cdot \mathrm{c}^{-1}$, в то время как в исследованных образцах она почти на порядок величины больше. В рамках простейшей модели энергия ионизации должна возрастать на величину $\Delta E=\hbar \omega_{c} / 2$, где $\omega_{c}-$ циклотронная частота. Для $B=4$ Тл оценки применительно к $\mathrm{PbSnTe}$, исходя из данных по величине эффективной массы электрона $m^{*}$, дают значения $\Delta E \approx 0.004-0.02{ }_{\text {э }} \mathrm{B}\left(\mathrm{m}^{*} / m_{0} \approx 0.01-0.05\right)$.

Рассмотрим поведение тока (рис. 4) в рамках сделанных предположений. Дырочный тип проводимости при освещении соответствует наличию уровней захвата для электронов, энергия ионизации которых увеличивается в сильном магнитном поле. К моменту выключения освещения значительная часть уровней с достаточно большими коэффициентами захвата заполнены электронами, и наблюдается дырочный ток, примерно на 2 порядка больший темнового. После выключения освещения в момент $t=417$ с наблюдается типичная для $\mathrm{PbSnTe}:$ In релаксация фототока, неэкспоненциальное поведение которой связано со сложным спектром ловушек. При выключении магнитного поля в момент $t=458$ с энергия ионизации ловушек уменьшается с резким увеличением темпа выброса электронов с ловушек. Это приводит сначала к „всплеску“ тока за счет добавления электронной компоненты проводимости при опустошении самых мелких уровней, которые тем не менее при $B=4$ Тл были достаточно „глубокими“ и заполненными неравновесными электронами. Далее, по мере более медленного опустошения все более глубоких уровней, происходит рекомбинация выброшенных с уровней электронов с дырками в валентной зоне и уменьшение проводимости. Динамика изменения тока на этом временно́м участке определяется сложным энергетическим спектром ловушечных уровней и отражается в виде особенностей на верхней вставке нижнего рисунка.

Последующее „включение“ магнитного поля при $t=464$ с возвращает энергию ионизации в исходное состояние, однако заполнение уровней прилипания неравновесными электронами в этом случае существенно меньше исходного, а величина тока близка к его значению при $t<220$ с, т.е. до освещения. Тем не менее ток остается несколько больше и продолжает медленно релаксировать к своему стационарному состоянию. Повторное выключение $B$ ускоряет этот процесс, однако наиболее мелкие уровни ловушек уже опустошены и плавная динамика тока (нижняя вставка) определяется уже выбросами электронов с более глубоких уровней, которые имеют большие постоянные времени. Из этого следует, что отличие характерных времен релаксации для верхних и нижних фрагментов кривой на нижнем рисунке при $t>450$ с обусловлено выбросом электронов с одних и тех же уровней, у которых магнитное поле увеличивает энергию ионизации, увеличивая тем самым среднее время выброса электронов.

\section{4. Заключение}

Таким образом, представляется, что на основе модели $\mathrm{PbSnTe}: \mathrm{In}$, основанной на положениях теории неупорядоченных систем, удается качественно описать не только температурную зависимость равновесных концентраций носителей заряда и снижение их подвижности при низких температурах, но и найти объяснение неравновесным BAX и релаксации тока в магнитном поле. Безусловно, эта модель основана на ранее развитых представлениях, например, таких как спонтанная диссоциация нейтральной примеси и механизм внедрения индия в PbSnTe, и результатах экспериментальных исследований.

\section{Список литературы}

[1] W.W. Anderson, IEEE J. Quant. Electron., QE-13 (7), 532 (1977).

[2] Б.А. Акимов, Б.А. Брандт, С.А. Богословский, Л.И. Рябова, С.М. Чудинов. Письма ЖЭТФ, 29 (1), 11 (1979).

[3] Б.М. Вул, И.Д. Воронова, Г.А. Калюжная, Т.С. Мамедов, Т.Ш. Рагимова. Письма ЖЭТФ, 29 (1), 21 (1979).

[4] В.С. Виноградов, И.Д. Воронова, Г.А. Калюжная, Т.Ш. Рагимова, А.П. Шотов. Письма ЖЭТФ, 32 (1), 22 (1980).

[5] B.A. Akimov, A.V. Dmitriev, D.R. Khokhlov, L.I. Ryabova. Phys. Status Solidi, 137 (9), 09 (1993).

[6] К.Г. Кристовский, А.Е. Кожанов, Д.Е. Долженко, И.И. Иванчик, D. Watson, Д.Р. Хохлов. ФТТ, 46 (1), 123 (2004).

[7] А.В. Галеева, Л.И. Рябова, А.В. Никорич, С.Д. Ганичев, С.Н. Данилов, В.В. Бельков, Д.Р. Хохлов. Письма ЖЭТФ, 91 (1), 37 (2010).

[8] А.Н. Акимов, Д.В. Ищенко, А.Э. Климов, И.Г. Неизвестный, Н.С. Пащин, В.Н. Шерстякова, В.Н. Шумский, В.С. Эпов. Автометрия, 49 (5), 86 (2013).

[9] Ю.В. Андреев, К.И. Гейман, И.А. Драбкин, А.В. Матвеенко, Е.А. Можаев, Б.Я. Мойжес. ФТП, 9 (10), 1873 (1975).

[10] И.А. Драбкин, Б.Я. Мойжес. ФТП, 15 (4), 625 (1981).

[11] Б.А. Волков, О.А. Панкратов. ДАН СССР, 255 (1), 93 (1980).

[12] Б.А. Волков, О.А. Панкратов. Письма ЖЭТФ, 42 (4), 145 (1985).

[13] И.И. Засавицкий, К. Лишка, Х. Хайнрих. ФТП, 19 (6), 1058 (1985).

[14] И.И. Засавицкий, Б.Н. Мацонашвили, О.А. Панкратов, В.Т. Трофимов. Письма ЖЭТФ, 19 (6), 1058 (1985).

[15] А.Н. Акимов, А.Э. Климов, И.Г. Неизвестный, В.Н. Шумский, В.С. Эпов. ФТП, 50 (4), 447 (2016).

[16] В.С. Виноградов, И.Д. Воронова, Т.Ш. Рагимова, А.П. Шотов. ФТП, 15 (2), 361 (1981).

[17] В.Л. Бонч-Бруевич и др. Электронная теория неупорядоченных полупроводников (М., Наука, 1981) с. 11.

[18] Н. Мотт, Э. Дэвис. Электронные прочессы в некристаллических веществах (М., Мир, 1982) с. 55.

[19] В.Ф. Гантмахер. Электроны в неупорядоченных средах (М., Физматлит, 2005) с. 90.

[20] P.W. Anderson. Phys.Rev., 102, 1008 (1956).

[21] M.H. Cohen, H. Fritzsche, S.R. Ovshinsky. Phys. Rev. Lett., 22, 1065 (1969). 
[22] Г.А. Калюжная, К.В. Киселева. В сб: Тр. ФИАН им. П.Н. Лебедева (М., Наука, 1987) 177, с. 5.

[23] К. Зеегер. Физика полупроводников, пер. с англ. под ред. Ю.К. Пожелы (М., Мир, 1977) с. 616.

Редактор Г.А. Оганесян

\title{
Solid solution PbSnTe : In - electron capture levels, galvanomagnetic properties and $\mathrm{THz}$ sensitivity
}

D.V. Ishchenko, A.E. Klimov, V.N. Shumsky, V.S. Epov

Rzhanov Institute of Semiconductor Physics,

Siberian Branch of Russian Academy of Sciences, 630090 Novosibirsk, Russia

\begin{abstract}
The model of $\mathrm{Pb}_{1-x} \mathrm{Sn}_{x} \mathrm{Te}$ : In solid solution based on the concepts of the theory of disordered systems is considered. The temperature dependences of the Fermi level and carrier concentration depending on the level of indium doping are calculated and compared with experimental results. The calculation of transient current-voltage characteristics in the injection mode and limitation by space charge at different voltage rates is carried out. This data is compared with the experimental results, and it is shown that the behavior of the characteristics is determined by electron capture parameters of localized states. The relaxations of the photocurrent in a magnetic field are explored and the relaxation mechanism under the assumption of the magnetic freezing out of the carriers is discussed.
\end{abstract}

